\title{
ANALISIS FAKTOR-FAKTOR YANG MEMPENGARUHI PERTUMBUHAN EKONOMI DI KABUPATEN KUTAI BARAT
}

\author{
Oleh: \\ Leonardo Dakori Karun \\ Magister Ilmu Ekonomi Fakultas Ekonomi Universitas Mulawarman \\ Sri Mintarti \\ Fakultas Ekonomi Universitas Mulawarman \\ Juliansyah \\ Fakultas Ekonomi Universitas Mulawarman \\ Jalan Tanah Grogot Gunung Kelua Samarinda Telepon +62541-749067
}

\begin{abstract}
The research was based on the reason for analyzing the factors that affect the economic growth that occurred in the West Kutai Regency. By using independent variables such as government expenditure, domestic investment, foreign investment and the amount of manpower, and also to testing and analyzing the influence of each independent variable on the dependent variable of economic growth.The analysis tools are quantitative analysis using multiple linear regression analysis with SPSS. Multiple linear regression analysis is used to determine how much influence government expenditure $\left(X_{1}\right)$, domestic investment $\left(X_{2}\right)$, foreign investment $\left(X_{3}\right)$, and the amount of manpower $\left(X_{4}\right)$ to The economic growth $(Y)$. Based on the analysis, the independent variables (government expenditure, domestic investment, foreign investment and amount of manpower jointly affect the economic growth in the West Kutai Regency, with constant values for the constants in the regression equation -1005.538 while the regression coefficient for government expenditure variable $\left(X_{1}\right)=1.894$; domestic investment $\left(X_{2}\right)=0.627$; foreign investment $\left(X_{3}\right)=0.083$; and amout of manpower $\left(X_{4}\right)$ $=32.142$.
\end{abstract}

Keywords: Government expenditure, domestic investment, foreign investment and the amount of manpower.

\begin{abstract}
Abstrak
Penelitian ini didasari alasan untuk menganalisis faktor-faktor yang mempengaruhi pertumbuhan ekonomi di Kabupaten Kutai Barat. Dengan variabel independen pengeluaran pemerintah, realisasi PMDN, realisasi PMA, dan jumlah tenaga kerja, selain itu juga untuk menguji dan menganalisis seberapa besar pengaruh masingmasing variabel independen terhadap variabel dependen-nya. Alat analisis yang digunakan adalah analisis regresi linier berganda dengan program SPSS. Analisis regresi linier berganda digunakan untuk mengetahui seberapa besar pengaruh pengeluaran pemerintah (X1), realisasi PMDN (X2), realisasi PMA (X3), dan jumlah tenaga kerja (X4). Berdasarkan analisis, variabel pengeluaran pemerintah, realisasi PMDN, realisasi PMA, dan jumlah tenaga kerja secara bersama-sama berpengaruh terhadap pertumbuhan ekonomi di Kabupaten Kutai Barat dengan nilai konstanta konstanta persamaan regresi sebesar-1005,538 sedangkan nilai koefisien regresi untuk
\end{abstract}


variabel pengeluaran pemerintah $(X 1)=1,894 ;$ realisasi $P M D N(X 2)=0,627$; realisasi $P M A(X 3)=0,083$; dan jumlah tenaga kerja $(X 4)=32,142$.

Kata Kunci: Pengeluaran pemerintah, realisasi PMDN, realisasi PMA, dan jumlah tenaga kerja.

\section{PENDAHULUAN}

Pertumbuhan ekonomi merupakan pertumbuhan output yang dibentuk oleh berbagai sektor ekonomi sehingga dapat menggambarkan bagaimana kemajuan atau kemunduran yang telah dicapai oleh sektor ekonomi tersebut pada suatu waktu tertentu. Pertumbuhan ekonomi menunjukan sejauh mana aktivitas perekonomian akan menghasilkan tambahan pendapatan masyarakat pada suatu periode tertentu, karena pada dasarnya aktivitas perekonomian adalah suatu proses penggunaan faktor-faktor produksi untuk menghasilkan output, maka proses ini pada gilirannya akan menghasilkan suatu aliran balas jasa terhadap faktor produksi yang dimiliki oleh masyarakat sebagai pemilik faktor produksi juga akan turut meningkat.

Pertumbuhan ekonomi mutlak harus ada, sehingga pendapatan masyarakat akan bertambah, dengan demikian tingkat kesejahteraan masyarakat diharapakan akan meningkat. Agar pertumbuhan ekonomi terus meningkat dan dapat dipertahankan dalam jangka panjang maka perlu diketahui faktor-faktor apa yang dapat mempengaruhi pertumbuhan ekonomi dan faktor apa yang perlu dihindari agar pertumbuhan ekonomi tidak berjalan ditempat atau mengalami kemunduran. Salah satu indikator untuk menilai pertumbuhan ekonomi dan perkembangannya di suatu daerah diantaranya adalah dengan melihat besarnya nilai investasi pemerintah dan swasta baik PMA dan PMDN, serta jumlah tenaga kerja yang dapat terserap. Pelaksanaan otonomi daerah yang lebih luas yang diterima sejak tanggal 1 januari 2001 perlu disikapi dengan cepat oleh Pemerintah Daerah dan masyarakat. Kewenangan yang lebih luas dalam disentralisasi penyelenggaraan pemerintah daerah menyangkut aspek-aspek administrasi, kelembagaan dan pengelolaan sumbersumber keuangan harus segera direalisasikan termasuk pengelolaan sumber penerimaan dan pengeluaran keuangan daerah. Selain itu menurut Widayat dalam Suhardi (2009 : 29). 
Hasil nyata dari berbagai kebijaksanaan terhadap pemerintah daerah di bidang keuangan daerah dapat dilihat dari perkembangan penerimaan dan pengeluaran daerah yang tertuang dalam APBD sebagai faktor penting pelaksanaan otonomi.

Pembangunan di Propinsi Kalimantan Timur, khususnya di kabupaten Kutai Barat yang berlangsung secara menyeluruh dan berkesinambungan telah meningkatkan perekonomian masyarakat. Pencapaian hasil-hasil pembangunan yang sangat dirasakan masyarakat merupakan hasil yang tidak terlepas dari usaha keras bersama-sama antara pemerintah daerah dan masyarakat, namun di sisi lain berbagai kendala dalam memaksimalkan potensi sumber daya manusia dan sumber modal masih dihadapi oleh penentu kebijakan di tingkat propinsi maupun di kabupaten/kota.

Jika dilihat dari pertumbuhan ekonomi Kabupaten Kutai Barat selama kurun waktu 5 tahun terakhir menunjukkan angka yang cukup baik dan stabil di kisaran 6,1 persen sampai dengan 7,85 persen. Namun apabila dilihat dari sisi komponen penyokong pertumbuhan ekonomi seperti nilai investasi baik asing maupun domestik pada satu tahun terakhir justru mengalami penurunan, ditambah dengan menurunnya jumlah penduduk yang bekerja di Kabupaten Kutai Barat selama empat tahun terakhir dari 82.445 jiwa pada tahun 2008 menjadi hanya sekitar 76.833 jiwa pada tahun 2010, dan meningkat lagi menjadi 84.828 iwa pada tahun 2011.

Untuk melihat lebih jelas mengenai perbandingan beberapa data tersebut dapat dilihat dalam tabel 1.

Tabel 1. Pertumbuhan Ekonomi, Pengeluaran Pemerintah, Investasi dan Jumlah Penduduk Yang Bekerja Tahun 2004-2011

\begin{tabular}{cccrrr}
\hline Tahun & $\begin{array}{c}\text { Pertumbuhan } \\
\text { Ekonomi } \\
(\%)\end{array}$ & $\begin{array}{c}\text { Pengeluaran } \\
\text { Pemerintah } \\
\text { (Rp. Juta) }\end{array}$ & $\begin{array}{c}\text { Investasi } \\
\text { PMA } \\
\text { (Rp. Juta) }\end{array}$ & $\begin{array}{c}\text { Investasi } \\
\text { PMDN } \\
\text { (Rp. Juta) }\end{array}$ & $\begin{array}{c}\text { Penduduk } \\
\text { Bekerja } \\
\text { (Jiwa) }\end{array}$ \\
\hline 2004 & 5.44 & 575646.77 & 5551.61 & 104698.42 & 64.822 \\
\hline 2005 & 8.24 & 572434.96 & 2972.02 & 41000.00 & 71.179 \\
\hline 2006 & 6.11 & 661281.59 & 31861.50 & 1165540.45 & 70.234 \\
\hline 2007 & 6.45 & 531901.47 & 193049.55 & 42647.53 & 81.044 \\
\hline 2008 & 6.83 & 592719.24 & 5496.74 & 774998.12 & 82.445 \\
\hline 2009 & 6.89 & 695637.65 & 134650.26 & 98000.00 & 81.478 \\
\hline 2010 & 6.10 & 81157.55 & 65809.43 & 988950.00 & 76.833 \\
\hline 2011 & 7.85 & 952195.68 & 28800.90 & 527300.00 & 84.828 \\
\hline
\end{tabular}

Sumber: Badan Pusat Statistik Kabupaten Kutai Barat, 2012 
Berdasarkan kondisi rata-rata laju pertumbuhan ekonomi yang yang tidak sebanding dengan jumlah investasi baik asing maupun dalam negeri, serta cukup fluktuatifnya kondisi perkembangan jumlah pengeluaran pemerintah dan jumlah penduduk yang bekerja.

Pertumbuhan Ekonomi Menurut Sukirno (dalam Rustiono, 2008 : 12) Pertumbuhan ekonomi dapat diartikan sebagai perkembangan kegiatan dalam perekonomian yang menyebabkan barang dan jasa yang diproduksi masyarakat bertambah dan kemakmuran masyarakat meningkat.

Pengeluaran pemerintah merupakan salah satu unsur permintaan agregat. Konsep perhitungan pendapatan nasional dengan pendekatan pengeluaran bahwa $\mathrm{Y}=\mathrm{C}+\mathrm{I}+\mathrm{G}+\mathrm{X}-$ $M$. Formula ini dikenal sebagai identitas pendapatan nasional. Variabel Y melambangkan pendapatan nasional, sekaligus mencerminkan penawaran agregat. Sedangkan variabel-variabel di ruas kanan disebut permintaan agregat. Variabel G melambangkan pengeluaran pemerintah (Government expenditure). Dengan membandingkan nilai $G$ terhadap Y serta mengamati dari waktu ke waktu dapat diketahui seberapa besar kontribusi pengeluaran pemerintah dalam pembentukan pendapatan nasional (Dumairy, 1996 : 161).

Pengeluaran Pemerintah dan Pertumbuhan Ekonomi Pengeluaran pemerintah (goverment expenditure) adalah bagian dari kebijakan fiskal (Sadono Sukirno dalam Rustiono, 2008 : 34) yakni suatu tindakan pemerintah untuk mengatur jalannya perekonomian dengan cara menentukan besarnya penerimaan dan pengeluaran pemerintah tiap tahunnya yang tercermin dalam dokumen APBN untuk nasional dan APBD untuk daerah/regional. Tujuan dari kebijakan fiskal ini adalah dalam rangka menstabilkan harga, tingkat output maupun kesempatan kerja dan memacu pertumbuhan ekonomi.

Investasi dan Pertumbuhan Ekonomi yaitu Investasi sebagai salah satu komponen penting dari Agregate Demand, (AD) merupakan suatu faktor krusial bagi kelangsungan proses ekonomi (sustainable development), atau pertumbuhan ekonomi jangka panjang. Pembangunan ekonomi melibatkan kegiatan-kegiatan produksi (barang dan jasa) di semua sektor-sektor ekonomi. 
[Pick the date]

Tujuan dari teori mikro mengenai perkembangan pengeluaran pemerintah adalah menganalisis faktorfaktor yang menimbulkan permintaan dan faktor-faktor yang mempengaruhi penawaran akan barang publik. Interaksi antara permintaan dan penawaran untuk barang publik menentukan jumlah barang publik yang akan disediakan melalui anggaran belanja.

Tenaga Kerja dan Pertumbuhan Ekonomi yaitu Tenaga kerja dalam pembangunan nasional merupakan faktor dinamika penting yang menentukan laju pertumbuhan perekonomian baik dalam kedudukannya sebagai tenaga kerja produktif maupun sebagai konsumen. Ketidakseimbangan dalam penyebaran penduduk anatar daerah yang menyebabkan tidak proporsionalnya penggunaan tenaga kerja secara regional dan sektoral akan menghambat pula laju pertumbuhan perekonomian nasional (Kusumosuwidho, 1981 : 193).

Pada penelitian ini kerangka konseptual dibentuk dari teori-teori dan penjelasan teori yang situasional yang menjelaskan bahwa pertumbuhan ekonomi dipengaruhi oleh faktor-faktor pengeluaran pemerintah, realisasi
PMDN dan PMA serta jumlah tenaga kerja. Secara keseluruhan dan bersamasama keterkaitan antara variabel dan peran variabel dependen (Y) yaitu Pertumbuhan Ekonomi, dan variabel variabel independen yaitu Pengeluaran Pemerintah (X1), Realisasi PMDN (X2), Realisasi PMA (X3), Jumlah Tenaga Kerja (X4), secara skematis dapat digambarkan sebagai berikut :

\section{METODE PENELITIAN}

Pengeluaran Pemerintah adalah total anggaran yang dialokasikan untuk pengeluaran pembangunan pemerintah daerah Kabupaten Kutai Barat dalam satu tahun anggaran dalam satuan miliar rupiah. Pertumbuhan Ekonomi adalah nilai perkembangan ekonomi yang di proxy dengan total output yang dihasilkan oleh daerah dalam satu tahun yang di resepresentasikan dengan nilai Produk Domestik Regional Bruto (PDRB) atas dasar harga konstan Kabupaten Kutai Barat dalam satuan miliar rupiah. Realisasi Penanaman modal asing (PMA) adalah total nilai penanaman modal asing di Kabupaten Kutai Barat dalam satu tahun dalam satuan miliar rupiah. Realisasi Penanaman modal Dalam Negeri $(\mathrm{PMDN})$ adalah total nilai penanaman 
modal dalam negeri di Kabupaten Kutai Barat dalam satu tahun dalam satuan miliar rupiah.Tenaga Kerja (TK) adalah banyaknya jumlah penduduk usia 15 tahun keatas yang bekerja pada semua sektor ekonomi di Kabupaten Kutai Barat dalam satuan jiwa.

Untuk memperoleh hasil pengujian apakah ada atau tidak pengaruh sebab akibat antara 2 (dua) atau lebih variabel bebas yang digunakan terhadap variabel tak bebas dalam rangka pengujian hipotesis sebagai jawaban untuk pemecahan permasalahan yang dikemukakan dalam penelitian ini, maka menurut Supranto (1983 : 189) harus dianalisis dengan alat analisis Regresi Linier Berganda agar dapat diketahui bagaimana variabel dependen dapat diprediksi melalui variabel independen secara individu.

\section{PEMBAHASAN}

Analisis yang digunakan dalam penelitian ini adalah penelitian data kuantitatif yang menggunakan peralatan statistik regresi linier berganda, data yang telah tersedia diolah dengan menggunakan alat bantu berupa program pengolahan data statistik SPSS (Statistical Package for Social Science) versi 17.00 for Windows. Hasil yang diperoleh akan ditampilkan secara instant, hal ini dilakukan untuk dapat mengurangi tingkat kesalahan baik human error maupun machine error dalam proses analisis.

Analisis Regresi, Untuk melihat pengaruh variabel independen terhadap variabel dependen balk secara bersamasama maupun untuk menentukan koefisien determinasi dan koefisien korelasi serta alat ukur Iainnya maka data-data yang telah tersedia akan dianalisis menggunakan alat analisis regresi linier berganda dalam program SPSS. Adapun rangkurnan dari hasil analisis regresi tersebut dapat dilihat pada tabel 2 .

Tabel 2. Descriptive Statistics

\begin{tabular}{lrrr}
\hline & \multicolumn{1}{c}{ Mean } & $\begin{array}{c}\text { Std. } \\
\text { Deviation }\end{array}$ & N \\
\hline PDRBadhk & 2809.1138 & 449.70415 & 8 \\
\hline Peng_pemerintah & 674.1225 & 143.24111 & 8 \\
\hline R_PMA & 58.5238 & 69.94285 & 8 \\
\hline R_PMDN & 467.8925 & 461.03221 & 8 \\
\hline Jml_TK & 76.6075 & 7.11395 & 8 \\
\hline
\end{tabular}

Berdasarkan tabel 2 terlihat bahwa variabel dependen (Y) yaitu Pertumbuhan ekonomi memiliki ratarata sebesar 2.809,114 milyar rupiah dengan standar deviasi sebesar 449,704, sedangkan untuk variabel independen $\mathrm{X}_{1}$ yaitu pengeluaran pemerintah memiliki rata-rata sebesar $\mathrm{Rp} 674,122$ milyar rupiah dengan standar deviasi 
sebesar 143,241, variabel independen $\mathrm{X}_{2}$ yaitu realisasi PMA memiliki ratarata sebesar 58,524 Milyar rupiah dengan standar deviasi sebesar 69,943, variabel independen $X_{3}$ yaitu Realisasi PMDN memiliki rata-rata sebesar 467,892 milyar rupiah dengan standar deviasi sebesar 461,032, variabel independen $\mathrm{X}_{4}$ yaitu jumlah tenaga Tabel 3. Model Summary

\begin{tabular}{|c|c|c|c|c|c|c|c|c|c|}
\hline \multicolumn{10}{|c|}{ Model Summary ${ }^{b}$} \\
\hline \multirow[b]{2}{*}{ Model } & \multirow[b]{2}{*}{$\mathrm{R}$} & \multirow[b]{2}{*}{$\begin{array}{c}\mathrm{R} \\
\text { Square }\end{array}$} & \multirow[b]{2}{*}{$\begin{array}{l}\text { Adjusted } \\
\text { R Square }\end{array}$} & \multirow[b]{2}{*}{$\begin{array}{l}\text { Std. Error } \\
\text { of the } \\
\text { Estimate }\end{array}$} & \multicolumn{4}{|c|}{ Change Statistics } & \multirow[b]{2}{*}{ Durbin-Watson } \\
\hline & & & & & $\begin{array}{c}\mathrm{R} \\
\text { Square } \\
\text { Change }\end{array}$ & $\begin{array}{c}\text { F } \\
\text { Change }\end{array}$ & $\mathrm{df} 1 \mathrm{df} 2$ & $\begin{array}{l}\text { Sig. F } \\
\text { Change }\end{array}$ & \\
\hline 1 & $.987^{\mathrm{a}}$ & .973 & .938 & 112.41086 & .973 & 27.258 & 43 & .011 & 1.863 \\
\hline
\end{tabular}

a. Predictors: (Constant), Jml_TK, R_PMDN, R_PMA, Peng_pemerintah

b. Dependent Variable: PDRBadhk

Berdasarkan tabel 3 memperlihatkan nilai korelasi 0,987 dan koefisien determinasi $0,973(97,3 \%)$. Hasil tersebut menggambarkan hubungan variabel $\mathrm{X}_{1}, \mathrm{X}_{2}, \mathrm{X}_{3}$ terhadap Tabel 4. Anova kerja memiliki rata-rata sebesar 76.608 jiwa dengan standar deviasi sebesar 7,114 , dengan masa analisis selama 8 tahun $(\mathrm{N}=8)$.

Selanjutnya untuk menjawab permasalahan penelitian dapat dilihat pada tabel 3 ringkasan model persamaan regresi (model summary).

\begin{tabular}{lllllll}
\hline ANOVA $^{\mathbf{b}}$ & & & & & \\
\hline & Model & $\begin{array}{c}\text { Sum of } \\
\text { Squares }\end{array}$ & df & Mean Square & F & Sig. \\
\hline 1 & Regression & 1377728.156 & 4 & 344432.039 & 27.258 & $.011^{\mathrm{a}}$ \\
\cline { 2 - 7 } & Residual & 37908.604 & 3 & 12636.201 & & \\
\cline { 2 - 6 } & Total & 1415636.761 & 7 & & & \\
\hline
\end{tabular}

a. Predictors: (Constant), Jml_TK, R_PMDN, R_PMA, Peng_pemerintah

b. Dependent Variable: PDRBadhk

Dari tabel Anova ${ }^{\mathrm{b}}$ diperoleh nilai $F$ sebesar 27,258 dengan nilai probabilitas $($ sig. $)=0,011$. Karena nilai sig. < 0,05 maka hipotesis diterima, artinya secara bersama-sama Pengeluaran pemerintah, Realisasi 
PMA, Realisasi PMDN dan Jumlah tenaga kerja berpengaruh signifikan terhadap pertumbuhan ekonomi di Kabupaten Kutai Barat, sehingga model persamaan regresi linier berganda tersebut signifikan (Riduwan dan Engkos, 2011 : 158).

Dari hasil analisis tersebut
dapat dinyatakan bahwa secara
bersama-sama keempat variabel
independen (Pengeluaran pemerintah,
Realisasi PMA, Realisasi PMDN, dan
jumlah tenaga kerja) berpengaruh
positif secara signifikan terhadap
pertumbuhan ekonomi pada tingkat
kepercayaan 95 persen. Sementara
secara individual hanya dua variabel
independen yang mempunyai pengaruh
yang positif dan signifikan terhadap
variabel pertumbuhan ekonomi pada
model persamaan regresi tersebut
dengan tingkat kepercayaan 95 persen,
yaitu variabel Pengeluaran pemerintah
dan jumlah tenaga kerja.

Uji Asumsi Klasik, Uji keabsahan asumsi ini juga digunakan untuk memperkuat analisis dari penaksiran yang dilakukan. Pengujian ini berkaitan dengan normalitas, ada atau tidaknya multikolinieritas, heterokedastisitas dan autokorelasi. Dari hasil output SPSS menunjukkan bahwa asumsi normalitas dan homoskedastisitas model persamaan regresi yang dibangun terpenuhi, hal ini ditandai dengan titik-titik observasi yang membentuk garis diagonal pada normal $P-P$ plot, dan tidak berpolanya titik observasi pada Scatterplot

\section{KESIMPULAN}

Dan uraian pada bab-bab terdahulu maka dapat ditarik kesirnpulan dari Hasil analisis menunjukkan bahwa variabel independen secara bersama-sama mempunyai pengaruh yang signifikan terhadap variabel dependen dalam hal ini pertumbuhan ekonomi, yang ditunjukkan dengan perhitungan $F_{\text {hitung }}$ sebesar 27,258 dengan tingkat signifikasi sebesar 0,005 , sehingga hipotesis diterima yaitu terdapat pengaruh yang signifikan antara variabel pengeluaran pemerintah, realisasi PMA, realisasi PMDN, dan jumlah tenaga kerja.

Dan hasil analisis data, maka diperoleh nilai koefisien determinasi $\left(\mathrm{R}^{2}\right)$ sebesar 0,973. Hal ini secara statistik dapat dikatakan bahwa model persamaan regresi yang digunakan termasuk kategori sangat baik, karena dari nilai koefisien determinasi tersebut 
menunjukan besarnya pengaruh variabel independen terhadap variabel dependen, sehingga koefisien determinasi 0,973 mempunyai arti bahwa didalam model persamaan regresi tersebut variabel pertumbuhan ekonomi dapat diterangkan sekitar 97,30 persen oleh variabel pengeluaran pemerintah, realisasi PMA, realisasi PMDN, dan jumlah tenaga kerja, sedangkan sisanya 2,70 persen dijelaskan oleh variabel lain yang tidak termasuk dalam model persamaan regresi.

Nilai konstanta untuk dalam persamaan regresi sebesar $-1005,538$ sedangkan nilai koefisien regresi untuk variabel pengeluaran pemerintah $\left(\mathrm{X}_{1}\right)=$ 1,894; realisasi PMA $\left(\mathrm{X}_{2}\right)=0,627$; realisasi PMDN $\left(\mathrm{X}_{3}\right)=0,083$; jumlah tenaga kerja $\left(\mathrm{X}_{4}\right)=320,142$.

Secara individual keempat variabel independen tersebut mempunyai pengaruh yang positif namun hanya variabel pengeluaran pemerintah dan jumlah tenaga kerja yang mempunyai pengaruh signifikan terhadap variabel dependen pertumbuhan ekonomi di Kabupaten Kutai Barat.

Adapun variabel independen yang paling dominan mempengaruhi pertumbuhan ekonomi dalam persamaan regresi yang terjadi adalah variabel pengeluaran pemerintah dengan nilai koefisien regresi yang terstandarkan $(\beta)$ sebesar 0,603 .

\section{DAFTAR PUSTAKA}

Arsyad, Lincoln. 1999. Ekonomi Pembangunan. Edisi Keempat. STIE YKPN Yogyakarta.

Badan Pusat Statistik (BPS). Kutai Barat Dalam Angka Beberapa Terbitan. Berbagai Edisi.

\begin{tabular}{lrr} 
& & Survei \\
\hline Sosial & Ekonomi & Daerah \\
Kabupatem & Kutai & Barat \\
Beberapa & Terbitan. & Berbagai \\
Edisi. & &
\end{tabular}

Boediono, 1999. Teori Pertumbuhan Ekonomi. Yogyakarta : BPFE UGM.

Dumairy, 1996. Perekonomian Indonesia. Jakarta : Penerbit Erlangga.

Kasmawati,2010. Faktor-faktor yang Mempengaruhi Permintaan Air Bersih di Kecamatan Melak Kabupaten Kutai Barat. Tesis, Program Pascasarjana, Ilmu Ekonomi Universitas Mulawarman, Samarinda.

Kusumosuwidho, Sisdjiatmo. 1981. Angkatan Kerja, Dasar-Dasar Demografi. Jakarta : Lembaga Demografi FEUI

Mankiw, N.Gregory.2000.Teori Makro Ekonomi.Ed.4, Jakarta: Penerbit Erlangga. 
[Pick the date]

Mangkoesoebroto, Guritno. 2001. Ekonomi Publik. Yogyakarta : BPFE.

Nurlina. 2004. Analisis Pengaruh Anggaran Belanja Rutin dan Aggaran Belanja Pembangunan Terhadap Pertumbuhan Ekonomi Nanggroe Aceh Darussalam. Tesis Tidak Dipublikasikan. Medan : Program Studi Magister Ekonomi Pembangunan Pascasarjana USU.

Pancawati, Neni, 2000. Pengaruh Rasio Kapital-Tenaga Kerja, Tingkat pendidikan, Stok Kapital dan Pertumbuhan Penduduk Terhadap Tingkat Pertumbuhan GDP Indonesia ; Jurnal Ekonomi dan Bisnis Indonesia Vol.15, No.02, Universitas Gajah Mada, 2000.

Prasasti, Diah, 2006. Perkembangan PDRB per kapita 30 Propinsi di Indonesia Periode 1993-2003: Pendekatan Disparitas Regional dan Konvergensi ; Jurnal Ekonomi dan Bisnis Indonesia Vol.21, No.4, Universitas Gajah Mada, 2006

Purba, Adearman, 2008. Analisis faktorfaktor yang mempengaruhi pertumbuhan ekonomi Di Kabupaten Simalungun, Universitas Sumatra Utara, 2008

Riduwan dan Engkos, 2011. Cara Menggunakan dan Memaknai Path Analysis (Analisis Jalur) Cetakan Ketiga, Alfabeta, Bandung

Rustiono, Deddy, 2008. Analisis Pengaruh Investasi, Tenaga
Kerja dan Pengeluaran Pemerintah Terhadap Pertumbuhan Ekonomi Di Propinsi Jawa Tengah. Tesis Magister Ilmu Ekonomi UNDIP. Samuelson, A. Paul \& Nordhaus, D. William. 1997. Mikroekonomi. Erlangga, Jakarta.

Suhardi, 2009. Pengaruh Perkembangan PDRB Sektor Perdagangan, Jumlah Penduduk dan JUmlah Perusahaan terhadapPenerimaan Pajak Reklame di Kabupaten Kutai Barat. Universitas Mulawarman, Samarinda

Sukirno, Sadono, 2000. Makro Ekonomi Modern: Perkembangan Pemikiran Dari Klasik Hingga Keynesian Baru. Raja Grafindo Pustaka

Supranto, Johanes, 1983. Ekonometrik Buku Satu, LPFE UI, Jakarta

Suryana, 2000. Ekonomi Pembangunan: Problematika dan Pendekatan. Penerbit Salemba Empat Edisi Pertama, 2000.

Tambunan, Tulus. 2001. Perekonomian Indonesia. Jakarta : Ghallia Indonesia.

Todaro, Michael. 2004. Pembangunan Ekonomi di Dunia Ketiga. Penerbit Erlangga Edisi Kedelapan, 2004.

Wibisono, Yusuf. 2005. SumberSumber Pertumbuhan Ekonomi Regional : Studi Empiris Antar Propinsi di Indonesia, 19842000. Jurnal Ekonomi dan Bisnis Indonesia Vol.02, Universitas Gajah Mada, 2005. 
[Pick the date]

Widayat Wahyu, 2000, Maksimisasi Pendapatan Asli Daerah Sebagai Kekuatan Ekonomi Daerah, Jurnal Akuntansi dan Manajemen, STIE-YKPN, Yogyakarta
Yuliarmi, Nyoman. 2008. Pengaruh Konsumsi Rumah Tangga, Investasi dan Pengeluaran Pemerintah Terhadap PDRB Propinsi Bali ; Bulletin Studi Ekonomi Vo.13 No.2 Tahun 2008, Universitas Udayana Denpasar. 